\title{
A Conceptual Framework for Analyzing Quality Gaps in Consulting Services
}

\author{
Chuan Shi", Vincent Omachnu \\ Department of Industrial Engineering, University of Miami, United States
}

Copyright $(2016$ by authors, all rights reserved. Authors agree that this article remains permanently open access under the terms of the Creative Commons Attribution License 4.0 International License

\begin{abstract}
This conceptual framework study is aimed at building a quality gap model from consulting service to identify the consulting service gap, analyze where these gaps come from and how to mitigate these gaps by expanding the previous gap analysis studies by Parasuraman, et al., $1985^{[1]}$. The study offers a more granular assessment of the gaps including the various encounter points in the consulting processes. The study identifies consulting services' quality gaps that are more nuanced to explain the crossroads between what clients expect and what consultants provide. During the study, a high-level flow chart and a gap model are designed to demonstrate the gaps among procedures of the consulting service. The findings of this study suggest that there are differences in the perceived level of satisfaction between consultants and clients. Despite such accounts that the literature has surprisingly few explanations for failures in consulting and the concept of this study based on consulting service experience and hypothesis, we surveyed both consultants and clients to evaluate the validation of the quality gaps and the correlations between gaps. Researchers are encouraged to future examine the presence of gaps in the client-consultant firm encounter that may be pertinent to our concept of quality in consulting service industry.
\end{abstract}

Keywords Consulting Quality, Quality Gaps, Service Quality, Quality Analysis, Conceptual Framework

\section{Introduction}

In order to adapt to the competitive market, companies and organizations need to develop viable strategies to improve their efficiencies and increase their profits. Today, with highly competitive markets and the growing complexity of business issues, solving a business problem becomes more difficult than ever before. What's more, for some complex business issues, the internal management may not recognize the problem. Under this circumstance, the professional consultants are needed. They help many companies to design and implement strategies and solve real problems to assure companies succeed in the competitive business environment. In the market share of consultancy, based on the Gartner's research ${ }^{[2]}$, the worldwide consulting service market increased $6.1 \%$ to $\$ 125.2$ billion in 2014 , from $\$ 118.1$ billion in 2013. The combined top five consulting market performers grew above market average, with a growth rate of $8.1 \%$, and a combined market share of $43.3 \%$ in 2014 . The next five consulting providers add another $9.0 \%$ share, to make the combined total top 10 market shares of $52.3 \%$, suggesting a nonfragmented and consolidating market, with increase due to organic and inorganic growth. The top 10 consulting service providers combined grew at a fast pace of $6.8 \%$ over the market. The top 200 service providers with consulting services hold $78.5 \%$ market share. Of the consulting market, $60.5 \%$ is yield by the top 20 consulting providers, after which the market share distribution from service providers ranked 21 through 200 starts to fragment, with individual provider market share ranging from $0.6 \%$ to $0.01 \%$ of the total market.

While the consulting industry is prosperous from the data above, we are getting increasingly accounts of failed consulting project (Appelbaum and Steed 2005 [3]; Klenter and Möllgard $2006^{[4]}$ ). From Panorama 2015 ERP report ${ }^{[5]}$ surveyed globally 562 participants from across the globe, $21 \%$ of companies are defining their projects as failures, and $11 \%$ of companies claim their consulting experience as dissatisfied and very dissatisfied. According to the research of David Seidl and Michael Mohe in 2007, the dissatisfactions are because the consulting industry differs in the sense that clients and consultants are using different communication systems, and they are structurally coupled through a third system to communicate. "Due to their different logics no transfer of meaning between the three discourses is possible. This contradicts the traditional notion of consulting as a means of providing solutions to the client's problems: neither is the consultant able to understand the client's problems nor is it possible to transfer any solutions into the client system". Therefore, identifying and mitigating consulting service gap is important to relieve consulting project failures. We apply gap analysis, identified by 
Parasuraman in $1985^{[1]}$ by analyzing the differences between what clients want and what consultants provide.

Many studies have examined the subject of quality in the professional service industry (Lewis and Brown $2012^{[6]}$, Heineke, $1995^{[7]}$, Harte and Dale, $1995^{[8]}$, Brown and Swartz, $\left.1989^{[9]}\right)$. An equally significant number of studies have examined the issues of quality from a practical as well as theoretical perspective (Harte and Dale, 1995 ${ }^{[8]}$, Ritsema van Eck-van Peet, et al., $\left.1992^{[10]}\right)$. Parasuraman et al., (1985) ${ }^{[1]}$ defined four main quality gaps in the professional service industry:

1. The difference between what customer expectations and what management's perception of customer's expectations.

2 . The difference between management perceived customer expectations and the firms' service quality specifications.

3. The difference between designed service quality and the actual service delivery.

4. The difference between the services delivery and the service communication between customers and vendors.

In order to measure quality in services sectors, Zeithaml et al. $(1990)^{[11]}$ developed SERVQUAL model, pointing out the main components of high quality service. The SERVQUAL model focus on 10 elements of service quality: (1) reliability; (2) responsiveness; (3) competence; (4) access; (5) courtesy; (6) communication; (7) credibility; (8) security; (9) understanding/knowing the customer; (10) tangibles. According to this model, service quality is defined and calculated as the gap between customer's expectations and perceptions. It is expressed as Relation 1.

$$
\mathrm{Q}=\mathrm{E}-\mathrm{P}
$$

Where $\mathrm{Q}$ is service quality, $\mathrm{P}$ is perceptions of the customer about delivered services, and $\mathrm{E}$ is expectations of the customer about delivered services. A negative score indicates better service performance of the customer's expectations, whereas a positive score suggests inappropriate quality of the services. "The smaller is gap numerically (more negative), the quality level of the services is higher, and the larger is the gap value (more positive), service quality is poorer" (Ebrahim Azizi, Davood Jafari, and Babak Farhang Moghadam 2014 ${ }^{[12]}$ ).

This paper extends Parasuraman's gap model to more specific gaps that fully depict the quality elements inherent in consultancy. On one hand, the reason for the gaps is a set of clients' expectations, such as firm's reputations, clients' need, and previous experience. On the other hand, consultants deliver the service based on their own past experience and their expectations of what clients' expected. Therefore, the differences between these two hands create the four general gaps noted earlier.

In the context of consulting, the critical few of the service are 1) lack of technical skills, 2) ineffective project management, 3) lack of communication, 4) hidden agendas, and 5) unreadiness for/resistance to change (Michael Mohe and David Seidl $2007^{[13]}$ ). First, if consultants were lack of necessary technical skills, not only consultants cannot finish their work, but also clients would have the perceptions that the consultants they hired are inability to solve problems. These perceptions will lead untrusted relationship between consultants and clients and finally the relationship will break up. Second, if consultants cannot manage their project well, they may get lost and didn't target on what they were suppose to do at a certain time. Clients would get mad when talking to a mess again and again, and finally clients would lose patient and confident to those consultants. The third element is the key for consultation success. The trusted relationship between consultants and clients would be easy to break up if consultants didn't understand clients' technical and emotional concerns and respond in appropriate ways. Besides, hidden agendas will be a serious issue as well since consultants are hourly paid. If the contract were extended, the first impression coming to clients' mind is whether these consultants hired are eligible enough to pay such a high salary, and this impression results distrust as well. Last but not the least, if clients notice consultants negate their belief or interest, clients would set barriers in their perceptions that the consultants they hired are not with them, even though clients just don't want to face the fact. Clients under this situation would lose confidence, refuse to communicate with consultants, and tend to end their relationship. Therefore, if one attends to these issues, the likelihood of the consulting projects success would be increase.

\section{Theoretical Framework}

The term service has long been used to denote the interplay between the customer and the service provider (Bitner, Booms, and Tetreault, 1990) ${ }^{[14]}$. It is a central concept within service research, as it provides the basic situation whereby the customer coproduces value through interaction with the organization's service delivery systems. In the often-cited definition, Surprenant and Solomon (1987) ${ }^{[15]}$ described the service encounter as "the dyadic interaction between the customer and the service provider firm." The related concept of the customer experience has also been frequently defined to only include direct and indirect contact between the customer and the service provider (e.g., Meyer and Schwager 2007) ${ }^{[16]}$. The central assumption underlying these conceptualizations is that the service encounter is dyadic in nature and that the customer assesses the firm in isolation.

The expectations and experiences of consultants and clients can provide special insight into the services evaluation process and perceived service quality. By measuring both professionals' and clients' perspectives, the differences in perceptions can be identified and characterized (Swartz and Brown, 1989) ${ }^{[9]}$. The first service quality analysis model was produced in the 1980s (Grönross, 1984) ${ }^{[17][18]}$, based on the individual's perception of the quality of a service. The clients compare their expectations with their experiences of the service, meaning "technical quality" (obtained by the user) and "functional quality" (how the 
service is provided), perceived through the filter of providers' image. Furthermore, the first Gap Analysis Model developed by the North American scholars Parasuraman, Zeithaml and Berry $(1985)^{[1]}$ from exploratory investigations, emerged from the supposition that the quality of a service is expressed based on the disconfirmation paradigm (Oliver, $1980^{[12]}$; Churchill and Surprenant, $1982^{[20]}$ ).

To identify the quality of consulting service, we can use transfer function to address the quality outcomes of a consulting project and quality gaps as follows:

$$
\mathrm{Q}_{\mathrm{i}}=\mathrm{f}\left(\mathrm{X}_{1}, \mathrm{X}_{2}, \mathrm{X}_{3}, \ldots, \mathrm{X}_{\mathrm{n}}\right)
$$

Where $\mathrm{Q}_{\mathrm{i}}$ represents Consulting Quality Outcome, and $\mathrm{Xi}$ indicates Independent Variables Identified by the Gaps, the elements of the above critical few.

\section{An Expanded Consulting Quality Gap Model}

The most widely used process model in consulting is the Six-Step Business Consulting Process Model from STZ Consulting: 1) define objective, 2) gather data and analyze, 3) evaluate data and align goals, 4) develop strategies and solutions, 5) implement solutions or results, and 6) monitor performance. The first step in the business consulting process involves consultants and clients interacting to deal with clients' goals and objectives. Both consultants and clients should work together to better define objectives for their organizations, and find out what the real goals are to achieve favorable outcomes. Next, clients may support consultants to collect relevant data from various departments for further analysis. After data analysis and setting goals, consultants may work with clients, as well as meeting other management teams in the organization, to develop strategic plans to reach those goals. If the management teams approve the strategic assumptions, clients shall support consultants to implement the solutions. After the implementations, consultants need to collect data again to monitor if the goals are achieved or not. If the goals couldn't be achieved, or if more improvements are needed, the business consulting process might be restart. Therefore, consultants usually work projects with clients for several months or even years through this cycle. Although there are only six steps in a typical business consultation, consultants may face many difficulties before they finish each project. This is because there are gaps between clients' expectations for the consulting services and the services they receive in each step. Figure.1 illustrates the gaps between consultants and clients during the consulting process. These gaps are risky because they would not only decrease the clients' expectations, but also accumulate errors in each step, which may result in consulting failure.

Before hiring a consultant team, client's expectations can be categorized from three perspectives: 1) the reputations of the consulting firms, 2) the needs of clients, and 3) clients' past consulting experiences. First, many consulting firms use their successful cases to advertise their achievements to earn fames, which give clients more confidence and high expectations in their consulting service. For clients, they believe a good public reputation and the successfulness of other companies' projects would help them better solve problems and add value to their organizations. Therefore, clients expect effective solutions after they pay an expensive consulting fee for the reputations. Second, clients will face many complex business problems that they don't have enough resources to solve, and therefore, they tend to hire knowledgeable consultants to help them solve these tough issues. Additionally, if clients have the needs of personnel issues, such as find political solutions in the organizations and reform their enterprises, they may also hire some specific consultant teams to help them design their plan. Third, if a client is a returned customer with a good memory from the past consulting experience, the client may also expect at least the same high-level performance consulting services.

For the Proposal Part in Figure one, there are two possible gaps during the process to define objectives. Gap one is the gap between consultants' designed assumptions and the real situations of the clients' organizations. Sometimes consultants define inappropriate objectives because they concentrate too much on the symptoms but overlook the root causes of the problems (if the root causes can be found and removed, the symptoms may be cured). Therefore, they may oversimplify the problems and designed band-aid solutions. If these solutions were implemented, the projects might fail to achieve goals. In order to mitigate the gap, two rules are proposed when making hypothesis: 1) fact-based hypothesizes and 2) logical reasoning. Fact is the basis of hypothesizes, and anything contrary to the fact won't work. Strong logical reasoning can help the consultants avoid logical loopholes when revising and amending the hypothesis. Using these two rules together can make the hypothesis agree with the reality and mitigate the potential gap. 
Table 3. Gap Model for the Consulting Industry

\begin{tabular}{|c|c|c|c|}
\hline $\begin{array}{c}\text { Gap } \\
\text { Number }\end{array}$ & Gap & Reasons & $\begin{array}{l}\text { Factors Influential in closing } \\
\text { the Gap for consultants }\end{array}$ \\
\hline 1 & $\begin{array}{l}\text { The assumptions consultants design vs. } \\
\text { the real situations of the clients' } \\
\text { organizations and the outside } \\
\text { environment }\end{array}$ & $\begin{array}{l}\text { Consultants define inappropriate } \\
\text { objectives }\end{array}$ & $\begin{array}{l}\text { Fact-based hypothesizes and } \\
\text { logical reasoning }\end{array}$ \\
\hline 2 & $\begin{array}{l}\text { Consultants' stated objectives vs. } \\
\text { consultants' unstated objectives }\end{array}$ & $\begin{array}{l}\text { Consultants may not aware some } \\
\text { other important objectives or didn't } \\
\text { claim some objectives on purpose } \\
\text { until the projects face some problems }\end{array}$ & $\begin{array}{l}\text { Be honest to client, obey MECE } \\
\text { rule when using analytical } \\
\text { tools, and appropriately using } \\
\text { communication skills and } \\
\text { teamwork abilities }\end{array}$ \\
\hline 3 & $\begin{array}{l}\text { The available data clients provide vs. the } \\
\text { required data consultants want }\end{array}$ & Required data is unavailable & $\begin{array}{l}\text { Make possible estimations or } \\
\text { change method by using } \\
\text { available data }\end{array}$ \\
\hline 4 & $\begin{array}{l}\text { The goals clients desire vs. the goals that } \\
\text { consultants can achieve }\end{array}$ & Clients hold unachievable goals & $\begin{array}{l}\text { More communication and } \\
\text { detailed analysis }\end{array}$ \\
\hline 5 & $\begin{array}{l}\text { The solutions finally implement vs. the } \\
\text { solutions consultants develop }\end{array}$ & $\begin{array}{l}\text { 1. Clients are not satisfied with } \\
\text { clients service attitudes } \\
\text { 2. Clients are not satisfied with the } \\
\text { solutions }\end{array}$ & $\begin{array}{l}\text { More communication is } \\
\text { needed to build strong } \\
\text { relationships with clients } \\
\text { 2. Understand what clients } \\
\text { really need }\end{array}$ \\
\hline 6 & $\begin{array}{l}\text { The solutions consultants develop vs. } \\
\text { the solutions required to solve clients' } \\
\text { problems }\end{array}$ & $\begin{array}{l}\text { The solutions consultants designed } \\
\text { cannot solve clients' problems }\end{array}$ & $\begin{array}{l}\text { Analyze root causes, clients' } \\
\text { own situations and positions } \\
\text { before designing solutions }\end{array}$ \\
\hline 7 & $\begin{array}{l}\text { Clients' expected results vs. clients' } \\
\text { perceived results }\end{array}$ & $\begin{array}{l}\text { Clients and consultants may hold } \\
\text { different ideas on a same project }\end{array}$ & $\begin{array}{l}\text { Keep communicating with } \\
\text { clients and updating with } \\
\text { clients to make sure both of } \\
\text { them are on the same page }\end{array}$ \\
\hline 8 & $\begin{array}{l}\text { The actual results vs. consultants } \\
\text { presumed results }\end{array}$ & \multirow{2}{*}{$\begin{array}{l}\text { 1. Inaccurate assumptions } \\
\text { 2. Accumulated errors in } \\
\text { previous steps } \\
\text { 3. Ineffective project } \\
\text { management } \\
\text { 4. Changed external } \\
\text { environments }\end{array}$} & $\begin{array}{l}\text { 1. Actively and honestly } \\
\text { communicate with clients } \\
\text { 2. Verify the effectiveness in } \\
\text { assumptions and } \\
\text { executions for each step } \\
\text { before moving to the next } \\
\text { step }\end{array}$ \\
\hline 9 & $\begin{array}{l}\text { Clients expected results vs. the actual } \\
\text { results }\end{array}$ & & \begin{tabular}{|ll} 
3. & $\begin{array}{l}\text { Gain supports from } \\
\text { executives and }\end{array}$ \\
management \\
4. & Keep an eye on the \\
outside business \\
environment and make \\
changes on time if \\
necessary
\end{tabular} \\
\hline 10 & Initial result vs. long-term results & $\begin{array}{l}\text { 1. Clients didn't fix the root causes } \\
\text { of the problems } \\
\text { 2. Solid control plans haven't been } \\
\text { clearly designed }\end{array}$ & $\begin{array}{|ll|}1 . & \begin{array}{l}\text { Try to build solutions to } \\
\text { deal with root causes if } \\
\text { necessary }\end{array} \\
\text { 2. } & \begin{array}{l}\text { Consultants need to } \\
\text { design solid control plans } \\
\text { before leave }\end{array} \\
\end{array}$ \\
\hline
\end{tabular}

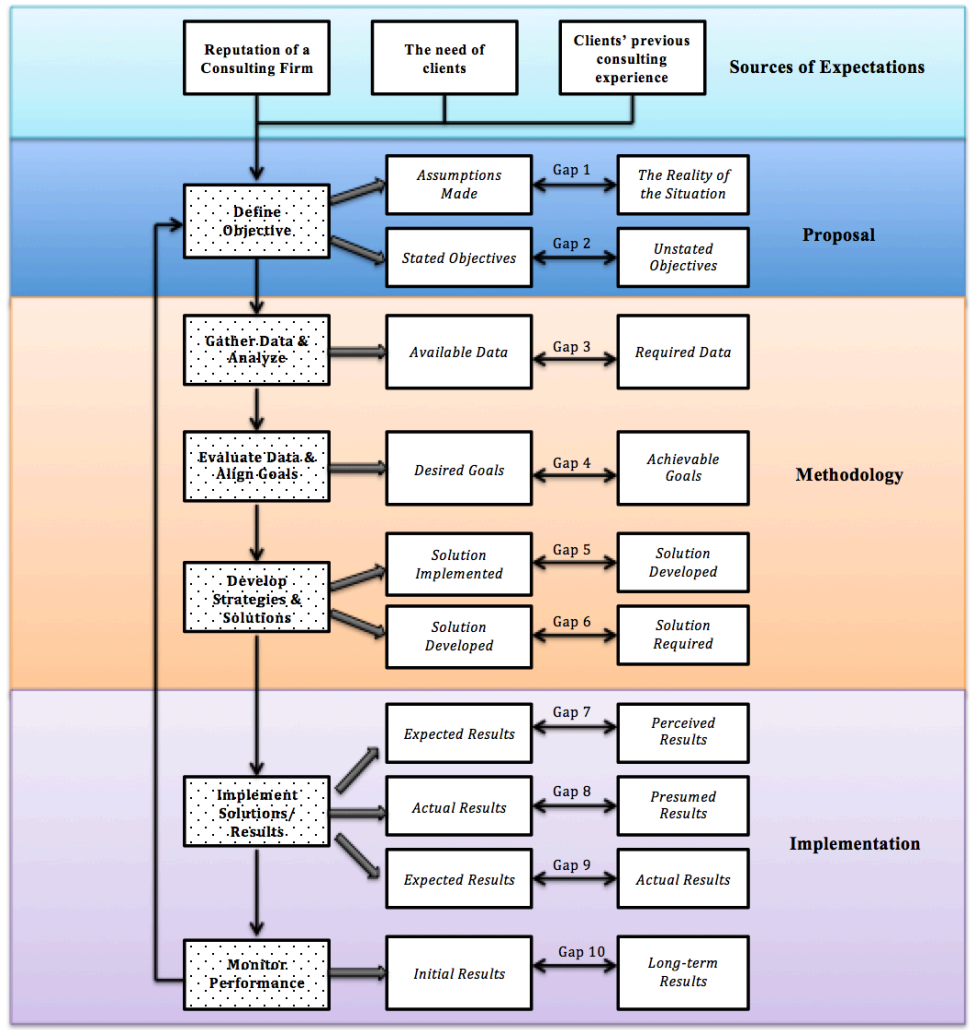

Figure 1. Clients' Expectation and Gaps in Each Step in Consulting Industry 
Gap two is the disparity between the objectives that consultants stated and unstated. The reason for this gap is that consultants may not aware some other important objectives or didn't claim some objectives on purpose until the projects face some problems. Sometimes consultants tell clients part of the objectives they are interested in instead of everything, which could incur defective proposals. Once the proposals are executed, the problems may appear and clients didn't expected what would happen and what measures they would do in a short time, which may delay the process of the projects. In order to mitigate this gap, consultants must first analyze clients' situations based on the facts and honestly present to clients the real situation with SWOT analysis based on the MECE rule (mutually exclusive and collectively exhaustive ${ }^{[21][22]}$ ). Other tools such as issue tree and flow chart may also be used in this stage. Besides, teamwork and communications play important roles in consultancy. Teamwork brainstorming, discussions, and critiques can help consultant teams locate and concentrate on the key points. Communicating with relevant departments leaders can help consultants make an accurate flow chart to find out the relations among Supply, Input, Process, Output, and Customer (SIPOC) ${ }^{[23]}$. With the help of the big map, consultants would build whole pictures of the processes to pinpoint the problems and draw a preliminary evaluation of the project. But before the proposals, it is possible that part of or even whole primary conditions cannot be executed, because of political, economic, personal reasons and so forth. Therefore, it is very important for consultants to talk with each of the management team about the proposal plans to make sure most of the managements like the plans. If the management team and the clients don't like the plan, consultants must think about clients' situations and communicate more with clients and managements to come up with practical proposals.

After clients accept the proposal, consultants would gather more detailed information and data to develop strategies and solutions. In the methodology section, there are four gaps. The first gap, Gap three, is between the available data clients providing, and the required data consultants need. Sometimes the required data is unavailable. This situation may happen in two possibilities: 1) no record for the required or and 2) some staff refuse to provide or have even provided consultants with incorrect data because of political situations. For the first situation, consultants could make possible estimations based on facts and available data, or change another method to gather other available data for the project. For the second situation, consultants and clients may seek other ways to gather data. Before using the gathered data, consultants also need to verify it to avoid using fictitious data. Otherwise, the wrong data may cause fallacious decisions and even fail projects.

Gap four is the gap between the goals that clients desire and the achievable goals that consultants can make. This gap is due to clients' holding unachievable goals. Sometimes clients want perfect plans to solve all of their problems in a short period. But for consultants, although they may show their successful consulting cases and give clients confidence to market themselves, they also need to honestly tell clients what can be done and what cannot be done. Therefore, consultants need more communication and analysis with clients to let them know their positions, available resources, outside environment, challenges and so forth.

When the goals are successfully aligned, consultants will advance to the step of developing strategies and solutions. However, if there is any proposal errors found in this step, this is the last time adjust to avoid fallacious implementations cost. There are two gaps in this step. Gap five is the difference between truly solutions implemented and solutions developed by consultants. The reason for this gap is that clients are dissatisfied with consultants' attitudes. For consultants' inappropriate service attitudes, if there are distrusts or misunderstandings between clients and consultants, clients may not be easy to accept the ideas from consultants. "Clients and consultants are conceptualized as two autopoietic communication systems that operate according to idiosyncratic logics. They are structurally coupled through a third system, the so-called "contact system", which constitutes a separate discourse. Due to their different logics no transfer of meaning between the three discourses is possible. This contradicts the traditional notion of consulting as a means of providing solutions to the client's problems: neither is the consultant able to understand the client's problems nor is it possible to transfer any solutions into the client system" (Michael Mohe and David Seidl 2007 $7^{[13]}$ ). Second, for the unacceptable solutions, it may also due to accumulated errors in the consulting process, the changed external environments, and clients' resource limitations. "Many implementation plans do not survive contact with reality" (Obolensky 2001, p. 177 $7^{[24]}$ ). Therefore, consultants need to establish a close relationship with clients to gain their trusts, understand what clients really need, and then try to build solutions with clients together. When building solutions, consultants need to build solutions according to internal and external environments and verify the effectiveness of assumptions and operations in each step to make sure clients are satisfied with each step.

Gap six shows the disparity between the solutions consultants develop and the required solutions to solve problems. "In yet other cases the consultants' recommendations have disastrous consequences for the organization" (O'Shea and Madigan 1997; Byrne 2002; Sorge and van Witteloostuijn 2004 ${ }^{[25]}$. As the former CEO of Volkswagen, Ferdinand Piëch, famously proclaimed: "If you want to ruin a company, you only have to try fixing it with the help of external consultants". This is because sometime consultants may design ineffective solutions that finally cannot solve clients' problems. In order to mitigate this gap, consultants should analyze root causes and clients' own situations and positions before designing proposals and solutions. Otherwise, after implement the solutions based on the inappropriate proposals, clients may be mad if the results are far from expected. 
In the implementation solution and result section, there are three gaps among the expected results, the actual results, the presumed results, and the perceived results. Gap seven is the gap between clients' expected results and clients' perceived results. The reason for this gap is that sometimes clients and consultants, based on their different experience and knowledge, may argue the methods they are going to use in the projects. This difference may lead clients' misunderstanding that the results are not the same as their expectations. Under this circumstance, consultants should listen to the opinions from clients and patiently communicate what they believe to find out ways that both clients and consultants are satisfied with. Additionally, consultants should keep updating changes with clients to make sure they are both in the same page.

Gap eight is the gap between actual results and the results consultants presumed because of some reasons, such as inaccurate assumptions, accumulated errors in previous steps, ineffective project management, and external environments. What's more, the most serious difference in the implementation section is gap night, the gap between clients' expected results and the actual results. One possible reason for these two gaps is consultants' over market themselves and solutions to try to meet clients' higher expectations and eliminate clients' concerns. But consultants may undermine their reputations if the implementation results are far from what consultant promise. In order to mitigate the three gaps in this step, consultants need to review four perspectives: 1) communications, 2) the solutions they created, 3) execution process, and 4) outside environments. First of all, the active and honest communications are the prerequisites of consulting to avoid misunderstanding. Sometimes clients may also critique the solutions if they are not satisfied, so consultants need to honestly communicate with clients to show what they are doing and why they choose those strategies. Otherwise, the doubts and misunderstandings may create obstacles for projects. Secondly, the created solutions may not be appropriate because the assumptions might not be clearly defined. Thus, errors in each step may be accumulated: if there were a mistake at the beginning or in the middle of processes, the answer would be wrong. In order to avoid created an invalid solution, consultants need to verify the effectiveness in assumptions and executions for each step to ensure everything works before moving to the next step. If there are unexpected obstacles, consultants should communicate with clients on time to find ways to solve the unexpected problems. Third, even though the strategies and plans are impeachable, careless and irresponsible execution would also impede the proceeding of projects. In order to successfully execute the solutions, clients may talk with executives or managements to earn their support so that the solution would be to be executed.
Last but not the least, if the outside situations change, such as policy and economic environment, the consulting project results may be affected as well. Under this circumstance, consultants and clients may need to make some changes on time to adapt the outside changes.

In the monitor performance section, even though the preliminary result is satisfied with clients' expectation, there is not guarantee that long-term results always follow the initial results, which is the Gap ten, the gap between the short-term results and the long-term results. This type of problems may appear after consulting because the consultants just focus on symptoms but didn't fix the root causes, or there are loopholes in the control plan, so that the result cannot be constant. In order to mitigate this gap, consultants may ask themselves why at least five times when making proposals and solutions to locate the root causes of the problems. Furthermore, consultants should also design a solid control plan to make sure each process has been controlled. The control plan should not only focus on the goals of the consulting projects, but also prevent new problems coming out.

\section{Gap Validation Survey and Analysis}

Despite the increasing number of critical articles both in the academic and business press, the literature on failure rates of consulting projects and the reasons behind them is very sparse. The little that is there is mostly written by practitioners, particularly by former consultants reflecting on their own experience (David Seidl and Michael Mohe, $2007^{[13]}$ ). In order to validate the conceptual framework of the quality gaps in the above gap model in consulting industry, a survey has been mad based on the interview with eight consultants, including two medical device consultants (with years of relevant consulting experience of 5 and 9, respectively), two management consultants (with years of relevant consulting experience of 3 and 5, respectively), two IT consultants (with years of relevant consulting experience of 3 and 4, respectively), and two healthcare consultants (with years of relevant consulting experience of 15 and 20, respectively). Additionally, there are also four clients receiving consulting services participating in the interviews, including a director of QA department from a class III medical device company, a manager from IT department of a university hospital, a director of rehabilitation department from a public hospital, and a vice president of a bicycle manufacturing company. The interviews were conducted with a Likert-scale survey on disparity and frequency for each gap (scores from 1, the lowest, to 5, the highest), respectively, aiming at understanding how the consultants evaluate these gaps in validity and frequency. The interviews were between 20 minutes to 30 minutes each. 
In the survey, since gap seven is the gap between clients' expected results and clients' perceived results, this gap should survey clients only. Additionally, although gap two, the gap between stated and unstated objectives, is only for consultants, client can also evaluate this gap because both consultants and clients have interactions in this step. For the rest of the gaps, since both clients and consultants directly participate the relevant gap activities, the interview surveyed the rest of the gaps for both clients and consultants. Table one and Table two show the interviewed survey data for consultants and clients, and Figure two graphs the average rate of gap disparity and frequency for consultant survey and client survey.

Table 1. Summary of Consultant Interview Data

\begin{tabular}{|c|c|c|c|c|c|c|c|c|c|c|c|c|c|c|c|c|c|c|c|c|}
\hline \multirow[b]{2}{*}{ Consultant } & \multicolumn{2}{|c|}{ Gap 1 } & \multicolumn{2}{|c|}{ Gap 2 } & \multicolumn{2}{|c|}{ Gap 3 } & \multicolumn{2}{|c|}{ Gap 4 } & \multicolumn{2}{|c|}{ Gap 5 } & \multicolumn{2}{|c|}{ Gap 6} & \multicolumn{2}{|c|}{ Gap 7 } & \multicolumn{2}{|c|}{ Gap 8} & \multicolumn{2}{|c|}{ Gap 9} & \multicolumn{2}{|c|}{ Gap 10} \\
\hline & Disparity & Frequency & Disparity & Frequency & $\begin{array}{l}\text { Disparity } \\
\end{array}$ & Frequency & $\begin{array}{l}\text { Disparity } \\
\end{array}$ & Frequency & Disparity & $\begin{array}{l}\text { Frequency } \\
\end{array}$ & Disparity & $\begin{array}{l}\text { Frequency } \\
\end{array}$ & Disparity & Frequency & Disparity & Frequency & Disparity & $\begin{array}{l}\text { Frequency } \\
\end{array}$ & Disparity & $\begin{array}{l}\text { Frequency } \\
\end{array}$ \\
\hline $\begin{array}{l}\text { Medical Device } \\
\text { Consultant } 1\end{array}$ & 5 & 5 & 4 & 4 & 2 & 1 & 5 & 5 & 2 & 3 & 2 & 2 & - & . & 2 & 2 & 3 & 2 & 3 & 3 \\
\hline $\begin{array}{l}\begin{array}{c}\text { Medical Device } \\
\text { Consultant 2 }\end{array} \\
\end{array}$ & 2 & 4 & 2 & 4 & 2 & 2 & 2 & 2 & 3 & 4 & 2 & 4 & $\cdot$ & - & 3 & 2 & 4 & 2 & 5 & 4 \\
\hline $\begin{array}{l}\begin{array}{l}\text { Management } \\
\text { Consultant } 1\end{array} \\
\end{array}$ & 4 & 4 & 4 & 5 & 2 & 1 & 4 & 4 & 3 & 3 & 3 & 3 & - & - & 4 & 3 & 4 & 3 & 5 & 4 \\
\hline $\begin{array}{l}\text { Management } \\
\text { Consultant } 2 \\
\end{array}$ & 5 & 4 & 4 & 3 & 1 & 1 & 5 & 3 & 3 & 2 & 2 & 4 & - & - & 3 & 2 & 4 & 2 & 4 & 3 \\
\hline IT Consultant 1 & 2 & 3 & 2 & 3 & 1 & 1 & 3 & 2 & 2 & 2 & 4 & 4 & - & . & 1 & 1 & 4 & 4 & 5 & 5 \\
\hline IT Consultant 2 & 2 & 2 & 2 & 4 & 1 & 1 & 2 & 3 & 1 & 2 & 4 & 5 & - & . & 2 & 1 & 3 & 4 & 4 & 5 \\
\hline $\begin{array}{c}\text { Healthcare } \\
\text { Consultant } 1 \\
\end{array}$ & 4 & 4 & 4 & 4 & 2 & 1 & 3 & 4 & 2 & 3 & 2 & 2 & - & - & 2 & 2 & 4 & 4 & 5 & 4 \\
\hline $\begin{array}{c}\text { Healthcare } \\
\text { Consultant 2 } \\
\end{array}$ & 5 & 4 & 5 & 5 & 1 & 1 & 4 & 4 & 2 & 4 & 2 & 3 & - & - & 2 & 3 & 5 & 4 & 5 & 5 \\
\hline Average & 3.625 & 3.75 & 3.375 & 4 & 1.5 & 1.125 & 3.5 & 3.375 & 2.25 & 2.875 & 2.625 & 3.375 & - & - & 2.5 & 1.875 & 3.625 & 2.625 & 4.25 & 3.875 \\
\hline $\begin{array}{l}\text { Standard } \\
\text { Deviation }\end{array}$ & 1.408 & 0.886 & 1.188 & 0.756 & 0.535 & 0.354 & 1.195 & 1.061 & 0.707 & 0.835 & 0.916 & 1.061 & - & - & 0.926 & 0.641 & 0.518 & 0.916 & 0.886 & 0.835 \\
\hline
\end{tabular}

Table 2. Summary of Client Interview Data

\begin{tabular}{|c|c|c|c|c|c|c|c|c|c|c|c|c|c|c|c|c|c|c|c|c|}
\hline \multirow{2}{*}{ Consultant } & \multicolumn{2}{|c|}{ Gap 1 } & \multicolumn{2}{|c|}{ Gap 2 } & \multicolumn{2}{|c|}{ Gap 3 } & \multicolumn{2}{|c|}{ Gap 4} & \multicolumn{2}{|c|}{ Gap 5 } & \multicolumn{2}{|c|}{ Gap 6} & \multicolumn{2}{|c|}{ Gap 7 } & \multicolumn{2}{|c|}{ Gap 8} & \multicolumn{2}{|c|}{ Gap 9} & \multicolumn{2}{|c|}{ Gap 10} \\
\hline & Disparity & Frequency & Disparity & Frequency & Disparity & Frequency & Disparity & Frequency & Disparity & Frequency & Disparity & $\begin{array}{l}\text { Frequency } \\
\text { F }\end{array}$ & Disparity & Frequency & Disparity & Frequency & Disparity & Frequency & Disparity & $\begin{array}{l}\text { Frequency } \\
\text { Fenteque }\end{array}$ \\
\hline Client 1 & 4 & 4 & 4 & 5 & 2 & 1 & 4 & 4 & 3 & 2 & 3 & 2 & 1 & 2 & 4 & 4 & 5 & 5 & 4 & 5 \\
\hline Client 2 & 3 & 4 & 4 & 3 & 1 & 1 & 4 & 3 & 2 & 2 & 5 & 4 & 1 & 1 & 4 & 4 & 3 & 4 & 3 & 4 \\
\hline Client 3 & 4 & 5 & 5 & 4 & 1 & 1 & 5 & 4 & 4 & 3 & 3 & 3 & 3 & 2 & 4 & 5 & 4 & 5 & 4 & 4 \\
\hline Client 4 & 4 & 4 & 4 & 4 & 3 & 2 & 5 & 5 & 4 & 4 & 4 & 3 & 2 & 3 & 5 & 4 & 5 & 5 & 5 & 5 \\
\hline Average & 3.75 & 4.25 & 4.25 & 4 & 1.75 & 1.25 & 4.5 & 4 & 3.25 & 2.75 & 3.75 & 3 & 1.75 & 2 & 4.25 & 4.25 & 4.25 & 4.75 & 4 & 4.5 \\
\hline $\begin{array}{l}\text { Standard } \\
\text { Deviation }\end{array}$ & 0.5 & 0.5 & 0.5 & 0.816 & 0.957 & 0.5 & 0.577 & 0.816 & 0.957 & 0.957 & 0.957 & 0.816 & 0.957 & 0.816 & 0.5 & 0.5 & 0.957 & 0.5 & 0.816 & 0.577 \\
\hline
\end{tabular}


Gap Validation Rating for Consulant

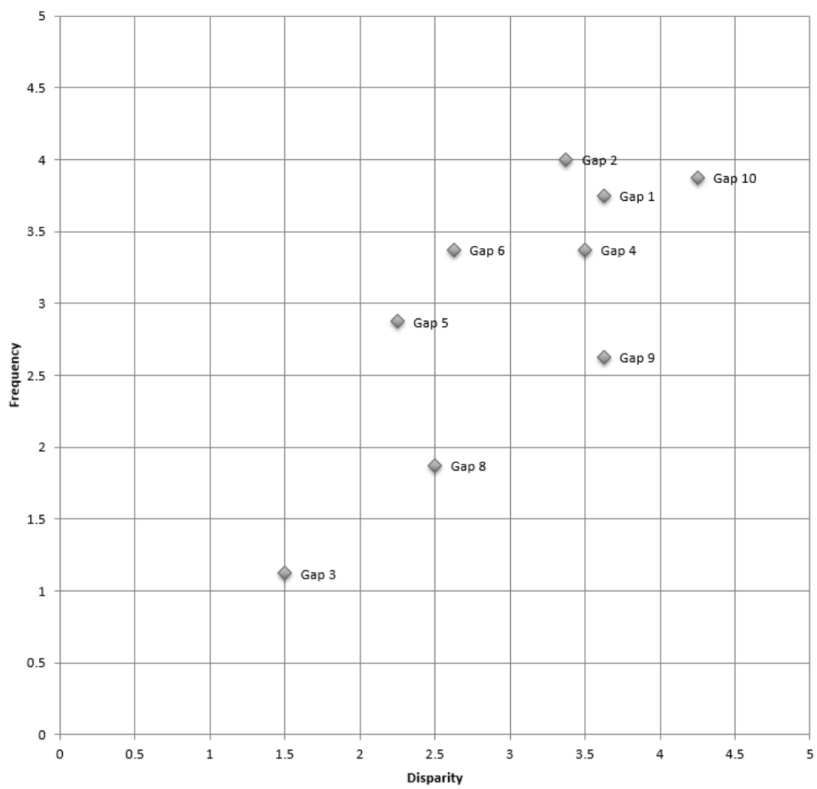

Gap Validation Rating for Client

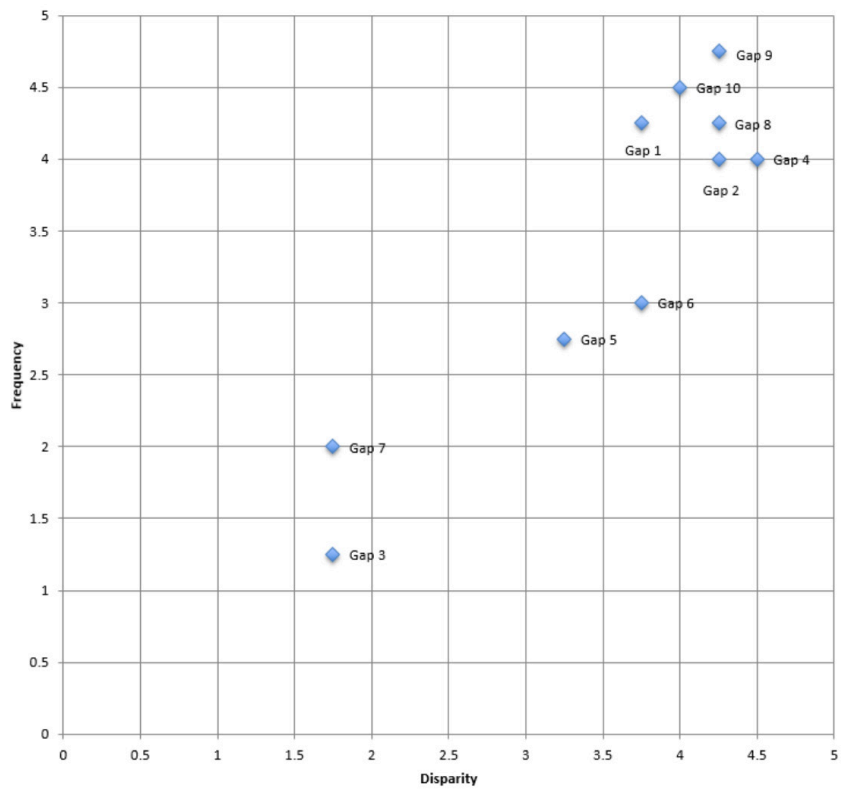

Figure 2. Consultants Gap Validation vs. Client Gap Validation

From Figure two, we notice that the consultants and clients hold different ideas on the validation of the gaps. For the area of both disparity and frequency greater than 2.50, we find the gap one, two, four, six, nine, and ten, which indicates that the interviewed consultants tend to believe the existence of these gaps. However, for clients, although they also agree with the gaps that consultants identify, they also agree with gap five, the gap between the solution implemented and the solution developed, and gap eight, the gap between the actual results and presumed result. This difference suggests the disparities where the gaps between consultants and clients in the consulting project come from. Furthermore, comparing with the rating value in disparity and frequency (except for gap seven), the ratings from clients show are always higher value than the ones from consultants, except the frequency ratings of gap five and six, and the disparity of gap ten, which have a slightly high rate for consultants'. The differences may indicate that clients may be more sensitive to experience the gaps in the consulting projects than consultants. However, in order to formally prove the above hypothesis, more studies have to be done.

Table 3. The Correlation Coefficients and P-value of Gap Disparity for Consultants

\begin{tabular}{|l|c|c|c|c|c|c|c|c|c|}
\hline \multicolumn{7}{|c|}{ Correlation Coefficient (Disparity for Consultants) } \\
\hline & Gap 2 & Gap 3 & Gap 4 & Gap 5 & Gap 6 & Gap 7 & Gap 8 & Gap 9 & Gap 10 \\
\hline Gap 1 & 0.950 & 0.095 & 0.891 & 0.251 & -0.678 & - & -0.603 & -0.613 & -0.372 \\
\hline Gap 2 & & 0.113 & 0.755 & 0.213 & -0.640 & - & -0.715 & -0.668 & -0.373 \\
\hline Gap 3 & & & 0 & 0.378 & -0.438 & - & -0.577 & -0.258 & -0.302 \\
\hline Gap 4 & & & & 0.338 & -0.457 & - & -0.258 & -0.577 & -0.405 \\
\hline Gap 5 & & & & & -0.496 & - & 0 & -0.098 & 0.114 \\
\hline Gap 6 & & & & & & - & 0.590 & 0.264 & -0.044 \\
\hline Gap 7 & & & & & & & - & - & - \\
\hline Gap 8 & & & & & & & & 0.447 & -0.044 \\
\hline Gap 9 & & & & & & & & & 0.856 \\
\hline
\end{tabular}

\begin{tabular}{|l|c|c|c|c|c|c|c|c|c|}
\hline \multicolumn{7}{|c|}{ P-value (Disparity for Conultants) } \\
\hline & Gap 2 & Gap 3 & Gap 4 & Gap 5 & Gap 6 & Gap 7 & Gap 8 & Gap 9 & Gap 10 \\
\hline Gap 1 & 0.0003 & 0.8231 & 0.0029 & 0.5486 & 0.0644 & - & 0.1137 & 0.1063 & 0.3641 \\
\hline Gap 2 & & 0.7908 & 0.0304 & 0.6132 & 0.0874 & - & 0.0464 & 0.0701 & 0.3626 \\
\hline Gap 3 & & & 1 & 0.3559 & 0.2782 & - & 0.134 & 0.537 & 0.468 \\
\hline Gap 4 & & & & 0.4128 & 0.2554 & - & 0.537 & 0.134 & 0.3202 \\
\hline Gap 5 & & & & & 0.2111 & - & 1 & 0.8182 & 0.7882 \\
\hline Gap 6 & & & & & & - & 0.1241 & 0.5281 & 0.9176 \\
\hline Gap 7 & & & & & & & - & - & - \\
\hline Gap 8 & & & & & & & & 0.2666 & 0.9176 \\
\hline Gap 9 & & & & & & & & & 0.0066 \\
\hline
\end{tabular}

Table 4. The Correlation Coefficients and P-value of Gap Disparity for Consultant

\begin{tabular}{|l|c|c|c|c|c|c|c|c|c|}
\hline \multicolumn{7}{|c|}{ Correlation Coefficient (Frequency for consultants) } \\
\hline & Gap 2 & Gap 3 & Gap 4 & Gap 5 & Gap 6 & Gap 7 & Gap 8 & Gap 9 & Gap 10 \\
\hline Gap 1 & 0.213 & 0.114 & 0.570 & 0.531 & -0.798 & - & -0.313 & 0.044 & 0.145 \\
\hline Gap 2 & & 0 & 0.5345 & 0.679 & -0.356 & - & -0.590 & 0.206 & 0 \\
\hline Gap 3 & & & -0.524 & 0.545 & 0.238 & - & 0.079 & -0.276 & 0.061 \\
\hline Gap 4 & & & & 0.222 & -0.778 & - & -0.552 & 0.165 & -0.101 \\
\hline Gap 5 & & & & & -0.424 & - & -0.568 & 0.304 & 0.385 \\
\hline Gap 6 & & & & & & - & 0.639 & -0.191 & -0.262 \\
\hline Gap 7 & & & & & & & - & - & - \\
\hline Gap 8 & & & & & & & & -0.578 & -0.568 \\
\hline Gap 9 & & & & & & & & & 0.864 \\
\hline
\end{tabular}

\begin{tabular}{|l|c|c|c|c|c|c|c|c|c|}
\hline \multicolumn{7}{|c|}{ P-value (Frequency for Consultants) } \\
\hline & Gap 2 & Gap 3 & Gap 4 & Gap 5 & Gap 6 & Gap 7 & Gap 8 & Gap 9 & Gap 10 \\
\hline Gap 1 & 0.6122 & 0.7882 & 0.1403 & 0.1756 & 0.0177 & - & 0.4483 & 0.9176 & 0.7322 \\
\hline Gap 2 & & 1 & 0.1723 & 0.0639 & 0.3863 & - & 0.1238 & 0.624 & 1 \\
\hline Gap 3 & & & 0.1827 & 0.1627 & 0.5702 & - & 0.8528 & 0.5087 & 0.8868 \\
\hline Gap 4 & & & & 0.5974 & 0.0231 & - & 0.1563 & 0.6955 & 0.8121 \\
\hline Gap 5 & & & & & 0.2956 & - & 0.1422 & 0.4647 & 0.3468 \\
\hline Gap 6 & & & & & & - & 0.0883 & 0.6496 & 0.5303 \\
\hline Gap 7 & & & & & & & - & - & - \\
\hline Gap 8 & & & & & & & & 0.1335 & 0.1422 \\
\hline Gap 9 & & & & & & & & & 0.0056 \\
\hline
\end{tabular}


What's more, by calculating the correlation coefficients and p-value between gaps, we can also find out the statistical connections between gaps. In this case, since the number of clients we interviewed is too few to calculate correlation, we only use the consultants' data. Table three and four show the data of correlation coefficients and p-values of both disparity and frequency. For the disparity tables, we find gap pairs one and two, one and four, two and four, and two and eight have statistical correlations. Meanwhile, for the frequency tables, we also find gap pairs one and six, four and six, and nine and ten have statistical correlations. However, the internal reasons why these pairs have correlations are unknown. In order to reveal the reasons, more studies need to be done.

\section{Conclusions}

Although much has been written about the quality in the consulting industry, this study drives into an unexplored aspect of the interactions between consultants and clients. The disparities between what clients want and what the clients receive, and their perceptions regarding satisfaction may result in some of the quality gaps. The definition of quality in the consulting services industry should take into account the gaps discussed in this paper. From the survey, we notice that the opinions and sensitivities for quality gaps in consulting industry between consultants and clients are different: consultants believe there are few disparities between available data clients provide and required data consultant want, solutions implemented and solution consultants develop, and actual results and the results consultants presumed, while for clients, they believe only the two gaps, the gap between available data clients providing and required data consultants want and the gap between clients expected results and clients presumed results, have few difference based on their experience. Furthermore, we do also find the correlation between gaps. From the reasons of quality gaps in consulting industry, we noticed that "in most cases failure is attributed to personal characteristics of the consultant and client (e.g. lack of skills), technical shortcomings (e.g. ineffective project management), unstable or bad consultant-client relationships (e.g. lack of communication), and/or socio-political aspects of the client organization (e.g. hidden agendas; unreadiness for/resistance to change). It is usually suggested that if one attends to these issues it is possible to increase the likelihood of the consulting interventions turning out to be successful" (Michael Mohe and David Seidl $2007^{[13]}$ ).

We do not make the claim that this is an exhaustive list of gaps, but rather that quality should be defined and evaluated in the context of these and other quality gaps inherent in consulting projects. We encourage future researchers to examine and explore the presence of other gaps in the client-consultant firm encounter that may be pertinent to our understanding of quality in consulting industry, as well as the impact of the gaps. The gaps identified in this conceptual frame study can be further analyzed with the aid of a comprehensive survey tool based on a larger sample size. In relying on interview data for this study, our primary goal was to encourage a discussion on consulting quality gaps. Additionally, more studies need to be done to reveal the different sensitivities between clients and consultants and the internal reasons why these gaps are correlated. Lastly, researchers are also encouraged to study the subtopics of the different sensitivities between clients and consultants and the internal reasons of the correlations between or among gaps.

\section{REFERENCES}

[1] Parasuraman A., Zeithaml V.A., Berry L.L., A Conceptual Model of Service Quality and Its Implications for Future Research, Journal of Marketing, vol. 49 (Fall), 1-50, 1985.

[2] Jacqueline Heng, Dean Blackmore, Julie Short (2015) Gartner Market Share Analysis: Consulting Services, Worldwide, 2014

[3] Steven H. Appelbaum, Anthony J. Steed, (2005) The critical success factors in the client - consulting relationship, Journal of Management Development, Vol. 24 Iss: 1, pp.68 - 93

[4] Klenter, G. and Möllgard, N. (2006) "Return of Consulting Value Added by the Consultants is All that Counts", in T. Deelmann and M. Mohe (eds.) Selection and Evaluation of Consultants (Mering: Hampp), pp. 139-157.

[5] Panorama 2015 ERP report, 2015 Panorama Consulting Solutions

[6] Lewis, M.and Brown, A., How different is Professional Service Operations Management?, Journal of Operations Management 30(1-2):1-11, 2012.

[7] Janelle Heineke (1995) Strategic operations management decisions and professional performance in U.S. HMOs, Journal of Operations Management, Volume 13, Issue 4, December 1995, Pages 255-272

[8] H.G. Harte, B.G. Dale, (1995) Improving quality in professional service organizations: a review of the key issues, Managing Service Quality: An International Journal, Vol. 5 Iss: 3 , pp.34 - 44

[9] Brown, SW and Swartz, TA (1989), A gap analysis of professional service quality, The Journal of Marketing, Vol. 53, pp. 92-98.

[10] H.P. Ritsema van Eck - van Peet, M. Broekhuis, M.J.J. Gruisen, (1992) Problems of Quality Management in the Professional Services, International Journal of Quality \& Reliability Management, Vol. 9 Iss: 7

[11] Parasuraman, A;Zeithaml, Valarie A;Berry, Leonard L, SERVQUAL: A Multiple-Item Scale For Measuring Consumer Perceptions of Service Quality, Journal of Retailing, Volume 64, Num 1, Spring 1988.

[12] Ebrahim Azizi, Davood Jafari, Babak Farhang Moghadam (2014) Gap Analysis between Customer Expectations and 
Perceptions of ETKA Organization's Service Quality Using Servqual Approach (Case Study: Pamizfam Sugar Company), Journal of Social Issues \& Humanities, Volume 2, Issue 3, March 2014

[13] Seidl, D., \& Mohe, M. (2007). The consultant-client relationship: A systems-theoretical perspective (No. 2007-06). Discussion Papers in Business Administration.

[14] Bitner, M. J., Booms B. H., Tetreault, M. S., The Service Encounter: Diagnosing Favorable and Unfavorable Incidents, Journal of Marketing, 54 (01), 71-84, 1990.

[15] Surprenant, C. F. and Solomon, M. R., Predictability and Personalization in the Service Encounter, Journal of Marketing, 51 (04), 86-96, 1987.

[16] Meyer, C. and Schwager, A.(2007), Understanding Customer Experience, Harvard Business Review, Vol.85, 117-26.

[17] Grönroos, C., A service quality model and its marketing implications. European Journal of Marketing, 18(4), 36-44, 1984.

[18] Grönroos, C., Service management and marketing: Managing the moments of truth in service competition. Lexington, Mass: Lexington Books, 1990.

[19] Oliver, R.L. (1980), A Cognitive Model of the Antecedents and Consequences of Satisfaction Decisions, Journal of Marketing Research, vol. 17(4): pg. 460-468, 1980.

[20] Churchill G.A., Surprenant C., An Investigation into Determinants of Customer Satisfaction, Journal of Marketing Research, vol. 19, pg. 491-504, 1982.

[21] Rasiel Ethan, The McKinsey Way, McGraw-Hill, 1999

[22] Rasiel Ethan, Friga, Paul N., The McKinsey Mind, McGraw-Hill, 2011.

[23] SIPOC (Suppliers, Inputs, Process, Outputs, Customers) Diagram Milwaukee, Wisconsin: American Society for Quality, Retrieved 2012-07-03, Online available from http://asq.org/service/body-of-knowledge/tools-sipoc

[24] Obolensky, N. (2001) "Implementation", in P. Sadler (ed.) Management Consultancy: A Handbook for Best Practice (2nd edition, London: Kogan Page).

[25] O'Shea, J. and Madigan, C. (1997) Dangerous Company: The Consulting Powerhouses and the Businesses they Save and Ruin (New York, NY: Times/Random House).

[26] Parasuraman A., Zeithaml V.A., Berry L.L., Servqual: A Multiple-Item Scale For Measuring Consumer Perceptions of Service Quality, Journal of Retailing; Spring 1988; 64, 1; ProQuest pg. 12

[27] Parasuraman, A., Berry, L. L., \& Zenithal, V. A. (1991), Understanding Customer Expectations of Service Sloan Management Review, spring, 39-48.

[28] Jacqueline Heng, Dean Blackmore, Julie Short, Market Share Analysis: Information Security Consulting, Worldwide, 2014, Gartner Dataquest Research, ID: G00271916, 22 April 2015.

[29] Michael von Uechtritz, Market Share Analysis: Information Security Consulting, Worldwide, 2013, Gartner Dataquest Research Note G00259708, 2014.

[30] IDC MarketScape: Worldwide Business Consulting Services 2014 Vendor Assessment, IDC \#246615, 2014.
[31] Lovelock C., Product Plus, McGraw-Hill, New York, 1994.

[32] Hakatie, Annaleena and Ryynänen, Toni, Managing Creativity: A Gap Analysis Approach to Identifying Challenges for Industrial Design Consultancy Services, Design Issues, Vol. 23, No. 1, pp. 28-46, 2007.

[33] GM Hampton, Gap analysis of college student satisfaction as a measure of professional service quality, Journal of Professional Services Marketing, Volume 9, Issue 1, 1993.

[34] Andrew Sturdy, Karen Handley, Timothy Clark, Robin Fincham, Management consultancy: boundaries and knowledge in action, 2009

[35] Weiss Alan, Process consulting: how to launch, implement, and conclude successful consulting projects: powerful techniques for the successful practitioner, Pfeiffer, 2002

[36] Philip Sadler, Management consultancy: a handbook for best practice, Kogan Page, 2001.

[37] Muthasamy, Kanesan. Letter., Using Service Gaps to Quality Attributes. 2nd ed. Vol. 23, 145-163, 2011.

[38] Swartz, T. A. and Brown, S. W., Consumer and Provider Expectations and Experiences in Evaluating Professional Service Quality, Journal of the Academy of Marketing Science, vol. 17, 189-195, 1989.

[39] Tichidi, Megan, and Yan Bo Li, Process and Quality Improvement Using Six Sigma in the Construction Industry. Journal of Civil Engineering and Management, vol. 18(2), 1989.

[40] Justine Fischgrund, and Vincent Omachonu, Quality in Construction: Identifying the Gaps, International Journal of Construction Engineering and Management (in press), 3(2), 2014.

[41] Andrew Sturdy, The Consultancy Process - An Insecure Business?, Journal of Management Studies, Volume 34, Issue 3, pages 389-413, 1997.

[42] Vincent K. Omachonu and Joel E. Ross, Principles of Total Quality, CRC Press, 2004.

[43] David C. Lane, Modelling as learning: A consultancy methodology for enhancing learning in management teams, European Journal of Operational Research, Volume 59, Issue 1, Pages 64-84, 1992.

[44] Lai Kit Chow, S. Thomas Ng, A fuzzy gap analysis model for evaluating the performance of engineering consultants, Automation in Construction, Volume 16, Issue 4, Pages 425435, 2007.

[45] Mary Jo Jackson, Marilyn M. Helms, Mohammad Ahmadi, Quality as a gap analysis of college students' expectations, Quality Assurance in Education, Vol. 19 No. 4, 2011.

[46] DeWayne J Kurpius, Dale R Fuqua, Thaddeus Rozecky, The consultancy process: A Multidimensional Approach, Journal of Counseling and Development, Volume 71, July/August, 1993.

[47] Bronowski, M. Non-typical customer expectations in consulting services, Foundation of Control and Management Sciences 6: 27-38, 2006.

[48] Bronowski, M. Models of customer expectations in consulting services, Foundation of Control and Management 
Sciences 7: 5-16, 2007.

[49] Ebrahim Azizi, Davood Jafari, Babak Farhang Moghadam, Gap Analysis between Customer Expectations and Perceptions of ETKA Organization's Service Quality Using SERVQUAL Approach (Case Study: Pamizfam Sugar
Company), Journal of Social Issues \& Humanities, Volume 2, Issue 3, March 2014

[50] Chingang Nde Daniel, Lukong Paul Berinyuy, Using the SERVQUAL Model to assess Service Quality and Customer Satisfaction 